\title{
Missile Mathematical Model and System Design
}

\author{
István PAPP ${ }^{1}$
}

\begin{abstract}
Recently, aerospace (flight) engineers, having more solid mathematical backgrounds, have become familiar with the newest results in control theory and are able not only to formulate control problems but also solve them without attracting the attention of control experts. Moreover, they try to apply new results in control theory to specific aerospace and missile guidance problems. As a result, control theory is losing its biggest supplier and, to a certain degree, this slows down its progress. [1] [2]
\end{abstract}

Keywords: mathematical, control, missile, equations of motion

\section{Introduction}

In general, a missile can be defined as an aerospace vehicle with varying guidance capabilities that is self-propelled through space for the purpose of inflicting damage on a designated target. These vehicles are fabricated for air-to-air, surface-to-air, or surface-to-surface roles. They contain a propulsion system, warhead section, guidance systems, and control surfaces, although hypervelocity missiles do not use warheads or control surfaces. The guidance capabilities of the different missiles vary from self-guided to complete dependence on the launch equipment for guidance signals. [2] [3]

\section{The Missile Mathematical Model}

Firstly, we need to define the concept of missile: a missile is defined as a space-traversing unmanned vehicle that contains the means for controlling its flight path. The guided tactical missiles are sometimes referred to according to their air speed relative to the speed of sound and their type of propulsion system. Generally, the highest rate of airspeed that can be reached safely and still ensure correct operation is considered as that missile's classification. [1]

The four general categories of guided missiles are:

- surface-to-surface;

- surface-to-air;

- air-to-surface;

- air-to-air. [1]

In essence, the general means of classification of a missile's airspeed is related to the speed of sound (or Mach 1), which varies with respect to the ambient temperature. Commonly, there are four groups that are considered in classifying a missile. These:

- subsonic: airspeeds less than Mach 1;

- sonic: airspeeds equal to Mach 1 ;

- supersonic: airspeeds ranging between Mach 1 and Mach 5;

- hypersonic: airspeeds exceeding Mach 5. [1] [3]

1 National University of Public Service, assistant lecturer; e-mail: pappi@uni-nke.hu, ORCID ID: orcid.org/0000-0002-2929-5864 
Table 1. Comparison of Weapon System Characteristics. [1: 92]

\begin{tabular}{|l|l|l|}
\hline Feature & Sparrow-type weapon & Bank-to-turn weapon \\
\hline Guidance Mode & Skid-to-Turn & Bank-to-Turn \\
\hline Control Surfaces & Wing Control & Tail Control \\
\hline Autopilot Sensors & Accelerometers & Accelerometer \\
\hline Maximum Acceleration & 45g’s (32 g’s per axis) & 100 g’s in pitch, 10 g's in yaw \\
\hline Guidance Delay & 0.75 sec & 0.40 sec \\
\hline Launch Speed & $0.5-2.0$ Mach & $0.5-2.0$ Mach \\
\hline Speed Range & $0.5-3.0$ Mach & $0.5-4.0$ Mach \\
\hline Maximum Roll Rate & Not Applicable & $\pm 600 \%$ sec \\
\hline
\end{tabular}

Especially the pitch/yaw plane rotational responses behave like a spring - mass damper system. Mathematically, this system reaction can be expressed in the form

$$
\frac{d^{2} y}{d t^{2}}+2 \zeta \omega\left(\frac{d y}{d t}\right)+\omega^{2} y=\omega^{2} u(t)
$$

Equation (1) can also be written in the usual frequency domain as follows:

$$
y(s) / u(s)=\omega^{2} /\left(s^{2}+2 \zeta \omega s+\omega^{2}\right)
$$

In the above equations, the notations are:

$$
\begin{aligned}
& y(\mathrm{~s}) \text { - output, } \\
& u(\mathrm{~s}) \text { - input, } \\
& \zeta \text { - damping ratio, } \\
& \omega \text { - frequency (rad/sec), } \\
& s \text { - Laplace operator (rad/sec). }
\end{aligned}
$$

The above continuous system can be constructed in a simulation as a feedback network that represents a load factor command system in pitch/yaw planes. Figure 1 represents a typical pitch/yaw network. [1] [4] [6]

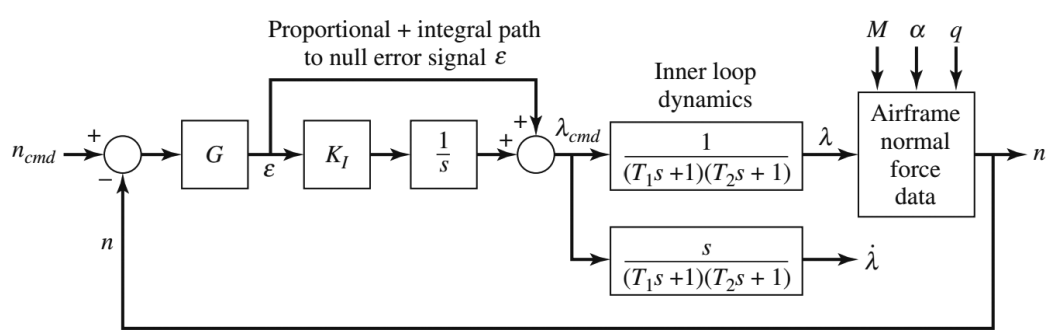

Figure 1. Pitch-yaw feedback network. [1: 93] 
Assume for simplicity that the missile's motion is constrained in the vertical plane. Furthermore, we will assume that the missile can be illustrated as a point mass. Therefore, from the missile's balanced forces shown in the diagram below, we can write the equations of motion as follows.

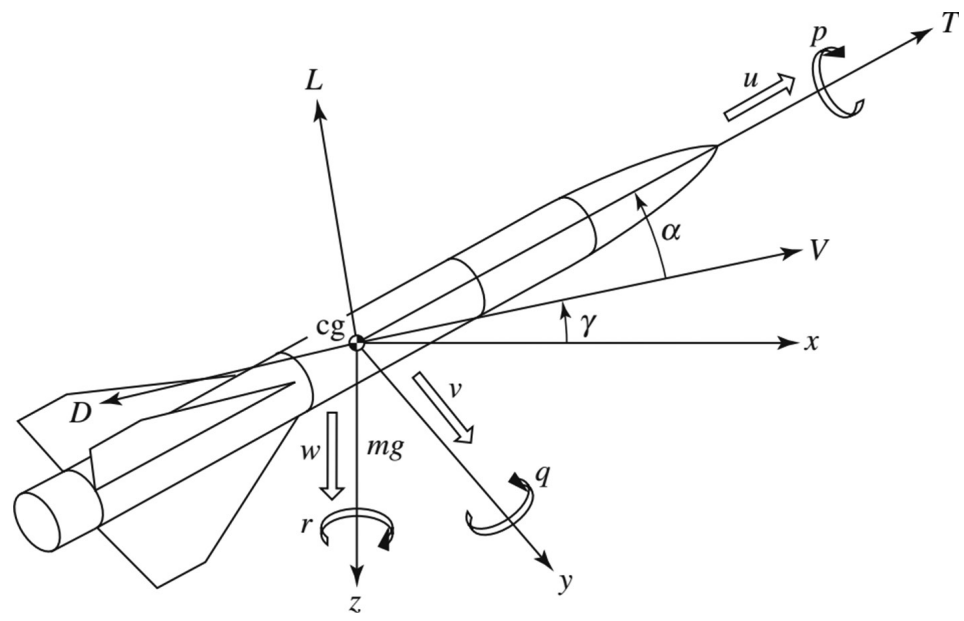

Figure 2. Missile balanced forces. [1: 98]

Based on Figure 2, we can write the following equations of motion:

$$
\begin{aligned}
& \frac{d V}{d t}=(1 / m)[T \cos \alpha-D]-g \sin \gamma \\
& \frac{d \gamma}{d t}=(1 / m V)[L+T \sin \alpha]-(g / V) \cos \gamma \\
& \frac{d x}{d t}=V \cos \gamma \\
& \frac{d h}{d t}=V \sin \gamma
\end{aligned}
$$

Aerodynamic Derivative Coefficients:

$$
\begin{aligned}
& L=\frac{1}{2} \rho V^{2} S C_{L} \\
& D=\frac{1}{2} \rho V^{2} S C_{D} \\
& C_{L}=C_{L \alpha}\left(\alpha-\alpha_{0}\right) \\
& C_{D}=C_{D 0}+k C_{L}^{2}
\end{aligned}
$$

where:

$g$ - acceleration of gravity,

$h$ - altitude,

$k$ - induced drag coefficient, 


$$
\begin{aligned}
& m \text { - mass, } \\
& D \text { - drag, } \\
& L \text { - lift, } \\
& M \text { - Mach number, } \\
& S \text { - reference area, } \\
& T \text { - thrust, } \\
& V \text { - velocity, } \\
& C_{D}, C_{L} \text { - drag and lift coefficients, } \\
& C_{D 0}-\text { zero-lift drag coefficient, } \\
& C_{L \alpha}-\partial C_{L} / \partial \alpha . \text { [1] [5] [9] }
\end{aligned}
$$

\section{System Design}

Specifically, the guided missile is typically divided into four subsystems:

- the airframe;

- guidance;

- motor (or propulsion);

- warhead.

Firstly, the type and size of airframe is strongly dependent on guidance characteristics, motor size, and warhead size.

Secondly, the type of guidance that can be used is also dependent on the motor, warhead, and threat. More specifically, the type of guidance chosen is dependent on the overall weapon system in which the missile will be used, on the type of threat the missile will be used against, the characteristics of the threat target, and other factors. Guidance, as we have seen earlier, is the means by which a missile steers or is steered to a target.

The next category is the motor, which characteristics are dependent on guidance requirements, the threat, and the airframe characteristics.

Finally, the warhead is dependent on the threat and type of guidance. Commonly, the procedure is to size the guidance requirements (e.g., accuracy, response time, range capability) from the threat, select an airframe that can deliver the required aerodynamic performance, size the motor based on threat and airframe considerations, and size the warhead according to guidance and airframe considerations. [1] [2] [5]

Figure 3 we can see an air-to-air missile’s general construction.

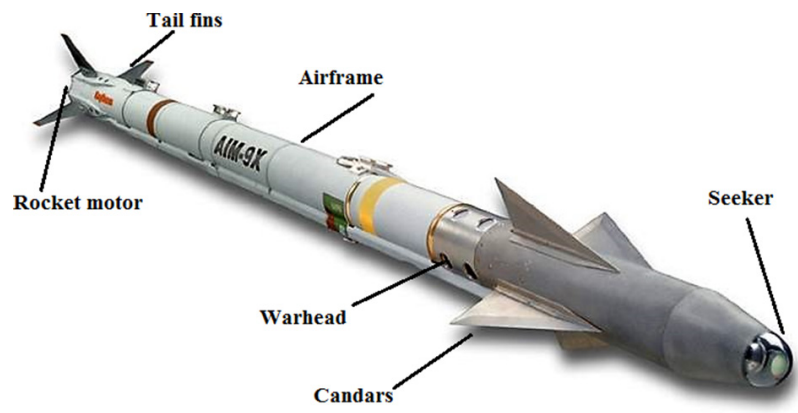

Figure 3. Air-to-air missile main parts.

[Edited by the author based on source 7.$]$ 
In addition to the above considerations, there are other basic factors that affect the design of any weapon system. These are:

- the threat;

- the operating environment;

- cost;

- state of the art.

Typically, the threat and operating environment are known or are given. Also, the state of the art is known. Therefore, the design effort of any missile centres on meeting the threat in the environment with the state of the art, at minimum cost. Consequently, three of these four factors are specified, with the fourth being either minimized (i.e., cost, state of the art) or maximized. [1] [2]

Figure 4 illustrates the above missile characteristics for an aerodynamic air-to-air missile.

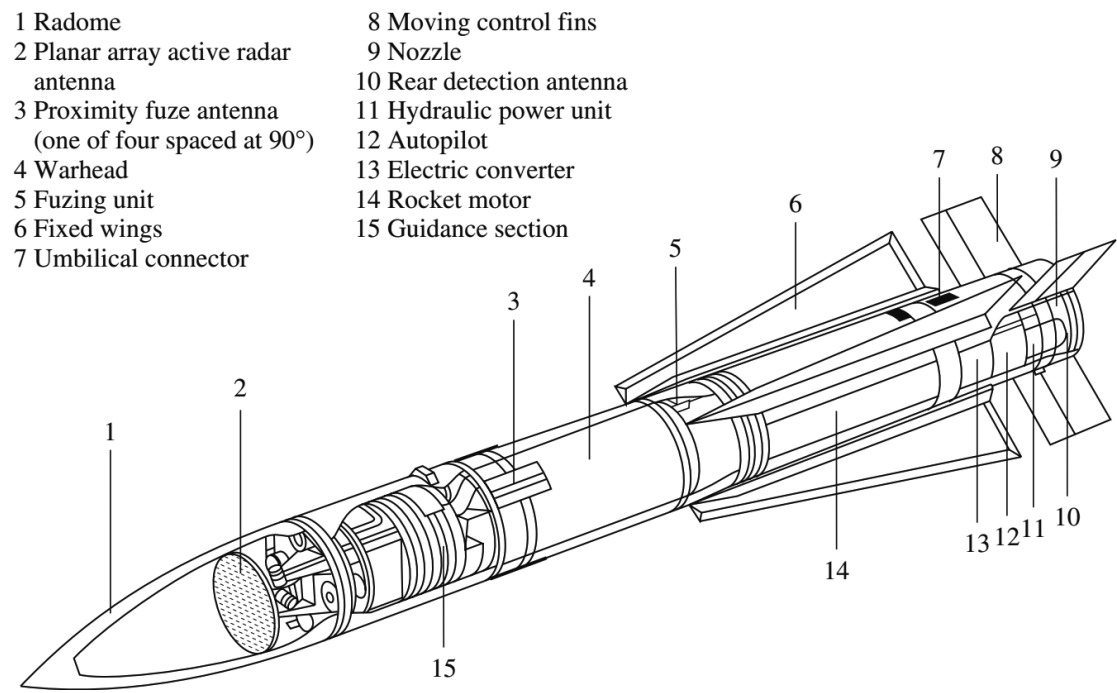

Figure 4. Basic missile construction. [1: 86]

In the development of the missile systems, a broad spectrum of engineering disciplines is employed with primary emphasis placed on the guidance and control subsystems. A comprehensive systems-oriented approach is applied throughout the system development. There are four basic phases in the development of a missile. Which are:

- concept formulation and/or definition;

- requirements;

- design;

- evaluation.

In diagram form, these four phases are shown in Figure 5.

Therefore, the missile system development cycle commences with the concept formulation, where one or more guidance methods are postulated and examined for feasibility and compatibility with the total system objectives and constraints. Surviving candidates are compared quantitatively and a baseline concept adopted. [1] [3] [5] 


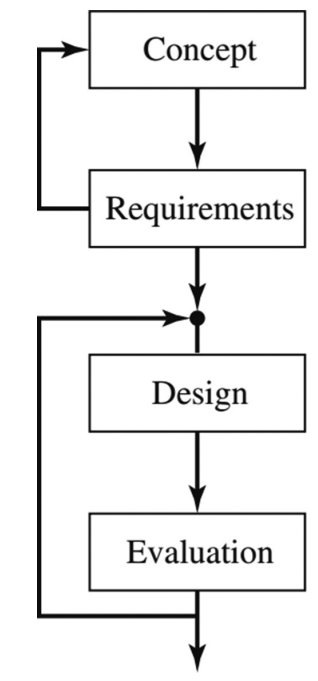

Figure 5. Missile development phases. [1: 89]

\section{Conclusion}

We can say that the process of guidance is based on the position and the velocity of the target relative to the guided object. The participants in the guidance process are also referred to in the literature as the evader and the pursuer, respectively. Most of the applications for the theory of guidance are in weaponry. The very fast progress of guided weaponry in the past fifty years would not be possible without advances in many technologies. One should mention internal combustion engines, rocket motors, inertial instrumentation (especially gyroscopes), aeronautics, electronics (especially microelectronics and radar), electro-optics, and computer engineering. [1] [6] [8]

\section{References}

[1] SIOURIS, G. M.: Missile Guidance and Control Systems. New York: Springer, 2003. http:// cdn.preterhuman.net/texts/terrorism_and_pyrotechnics/rocketry/Missiles_and_Warheads/ Missile\%20Guidance\%20\&\%20Control\%20Systems.pdf (Downloaded: 1507 2015)

[2] YANUSHEVSKY, R.: Modern Missile Guidance. Boca Raton: CRC Press, Taylor \& Francis Group LLC., 2008. DOI: https://doi.org/10.1201/9781351202954

[3] BALL, R. E.: The Fundamentals of Aircraft Combat Survivability Analysis and Design. Virginia: Virginia Polytechnic Institute and State University Blacksburg, 1985.

[4] PALUMBO, N. F., BLAUWKAMP, R. A., LLOYD, J. M.: Modern Homing Missile Guidance Theory and Techniques. Johns Hopkins APL Technical Digest, 291 (2010), 42-59.

[5] LIN, C. M., HSU, C. F., CHANG, S. K., WAI, R. J.: Guidance: Law Evaluation for Missile Guidance Systems. Asian Journal of Control, 24 (2000), 243-250. DOI: https:// doi.org/10.1111/j.1934-6093.2000.tb00029.x

[6] SHNEYDOR, N. A.: Missile Guidance and Pursuit: Kinematics, Dynamics and Control. Chichester: Horwood Publishing Chichester, 1998. 
[7] Scimitar Missiles, USS Sanctuary. Obsidian Portal. https://uss-sanctuary.obsidianportal.com/ wiki_pages/scimitar-missiles (Downloaded: 2003 2016)

[8] PAPP I.: Rakétahajtóművek üzemeltetésének biztonsági megoldásai. Repüléstudományi Közlemények, XXIV 2 (2012), 616-621.

[9] PAPP I., SZILVÁSSY L, ÓVÁRI Gy.: Derivation of the Fundamental Missile Guidance Equations. AARMS, 144 (2015), 341-348. 